\title{
The Role of Deductive and Inductive Reasoning in Accounting Research and Standard Setting
}

\author{
Hasan Zalaghi \\ Assistant Professor, Accounting Department, Buali Sina University, Hamedan, Iran \\ E-mail: Zalaghi@basu.ac.ir
}

Mahdi Khazaei (Corresponding author)

Accounting Department, Buali Sina University, Hamedan, Iran

E-mail: m.khazaei92@basu.ac.ir

Received: Nov. 5, 2015 Accepted: Dec. 9, $2015 \quad$ Published: June 1, 2016

doi:10.5296/ajfa.v8i1.8148 URL: http://dx.doi.org/10.5296/ajfa.v8i1.8148

\begin{abstract}
Accounting has been offered as an academic discipline in universities and higher education institutions for more than a century. For the first time in history, the American Institute of Accountants (AIA) puts forth efforts to compile the generally accepted accounting principles back in 1939. Since then, we have witnessed more efforts in setting accounting standards along with an expansion of the accounting theory and academic research studies. All of the mentioned efforts are signs of the fact that accounting is going through a change, from a profession into a field of science. However, one cannot claim accounting as a scientific field without justification, reasoning, and argumentation. Thereby, in this article while studying the deductive and inductive reasoning, we will elaborate their role in developing the accounting theory, setting the accounting standards, and accounting research. What has been expected from the accounting theory is to enable the standard setting authorities to deduce standards. Considering the impact of accounting theory on standard setting, the main aim of this study is to explore the role of deductive and inductive reasoning in the development of accounting theory and setting accounting standards. Furthermore, regarding the fact that accounting research is the joint connection between accounting theory and standards, the role of these reasoning approaches on the integrity of this connection is studied. This non-empirical research is based on reviewing of the existing literature.
\end{abstract}

Keywords: deductive reasoning, inductive reasoning, accounting theory, accounting standards. 


\section{Introduction}

The significance of this article stems from the necessity of making the infrastructures of accounting knowledge more scientific. The infrastructures would be the basis of assumptions, principles, and concepts of accounting knowledge. Only via making these infrastructures scientific, one can promote the status of accounting among other sciences. In addition, without any justification, reasoning, and argumentation, one cannot have scientific claims. The theory of accounting should ultimately enable the standards setters to deduce the standards. Considering the impact of accounting theory on standard setting, this article aims at analyzing the point that whether the type of reasoning applied in developing accounting theory and setting accounting standards is a deductive or inductive one. Also, considering the fact that accounting research is the joining point of accounting theory and standards, the role of deductive and inductive reasoning in the integrity of this connection is studied.

Deductive reasoning constitutes a valid reasoning by which it is impossible to accept the premises but reject the conclusion. The deductive approach in constructing the theory of accounting starts with specifying the objective. As soon as the objective is specified, the definitions and assumptions should be clarified. Next, the researcher will develop a logical structure based on the definitions and assumptions in order to reach the objective. This methodology is usually moving from the general to the specific, since the researcher needs to develop a logical structure to achieve the objectives which are based on the definitions and assumptions. The validity of any theory that deduced from this process is extremely dependent on the ability of the researcher in identifying the various components of accounting process and their interrelations in a logical way.

Induction is a reasoning method by which a law or a general principle would be inferred via observing specific cases. The inductive approach emphasizes on observation and deriving conclusions through observation. It generally moves from specific to general, since the researcher generalizes his limited observations of specific circumstances to general conditions. In accounting, the inductive approach begins by observing the financial information of the companies and progresses towards constructing accounting generalizations and principles out of those observations and re-occurring relations.

In deductive approach, in order to achieve a consensus, the structure of logical reasoning needs to be quite formal. However, in inductive approach, the accounting practice can turn into accounting principles. Accounting standard setters, extracted the conceptual framework via the best practices which in turn have been identified based on the assumed objectives of financial reporting. At the same time, attention was paid to the conceptual integrity, because the framework has been developed descriptively, although the objective was to make an imperative framework for providing guidelines to set and interpret accounting standards (Krivogorsky, 2011).

In accounting research, applying the inductive approach is usually intertwined with qualitative methods of collecting and analyzing the data, while the deductive approach is usually related to quantitative methods (Neuman, 1997). In inductive approach, there is no theory at the beginning of the research, and theories develop and evolve as a result of 
research (Babbie, 2014). As far as theorizing is concerned, the method of reasoning is of great importance. The early theorists' preference was to apply the inductive approach based on the observations of real practices. But, gradually, the theory of financial accounting was affected by economic thinking and the deductive approach became the dominant approach. Regarding standard setting, while there are various merits and demerits of both approaches of reasoning, the main difference between them is the point that the inductive approach suggests applying old solutions to new problems, while the deductive approach has a tendency to apply new solutions to old problems (Graham and Carmichael, 2012).

The article is structured as follows: first the deductive and inductive approaches in accounting are introduced and then the role of these approaches in accounting research, advancing the theory of accounting, and setting the accounting standards is discussed consecutively. Finally, the discussion and conclusion will be presented.

\section{Inductive approach}

Inductive approach begins with specific observations and the conclusions are generalized. In inductive approach, after selecting a number of observations correctly, one can generalize the conclusion to all or groups of similar conditions and situations. These generalizations need to be tested, some of which might be verified and some rejected. Accordingly, all of the principles which are derived based on inductive reasoning are theoretically falsifiable. In the induction process, the researcher as an observer, should honestly, without any prejudgments and biases, and with an impartial mind, register what they observe. Then these observations form a basis on which theories and laws are constructed which make up the scientific knowledge. Inductive researchers also believe that one can logically generalize the observations into general and inclusive rules and the scientific assumptions get verified and ratified (Godfrey and Hudson, 2010).

According to the inductive approach, at the end of research and as a result of observations, theories are constructed. The inductive approach includes looking for a pattern based on the observations and developing a theory for those patterns through hypotheses (Bernard, 2011). In inductive research, no theory is applied at the beginning of the research and the researcher enjoys complete freedom in terms of determining the course of research. Particularly, there is no assumption at the early stages of research and the researcher is not sure about the kind and the nature of findings as research is not finished yet. In inductive reasoning the researcher uses the observations in order to construct an abstract or to describe the circumstances being studied. (Lodico et al., 2010).

The main advantage of the inductive method is that there is no necessity for any pre-fabricated framework or model. Obviously, while principles are generalized they should be verified through a logical method (deductive approach). The inductive approach towards science has been criticized concerning some aspects. The main issue of the inductive method can be the researchers' being influenced by their limited knowledge of the relations and the data of the research (Saghafi, 2014). Some claim that induction as a principle is falsifiable because it is based on human observations. Kant, the German philosopher, defined a different philosophy that addressed the ontological issues for the first time and questioned the 
correspondence theory of truth. No scientist or philosopher living before Kant had doubted that truth is the correspondence between objective concept and reality (external subject). Nevertheless, Kant believed observation to be an interpretive activity, i.e. we interpret our experience or observation of the world within our cultural and individual frameworks. This means that the world as represented by science has originated from the realities outside of our existence to some extent, however a part of it has originated from our classifications of the world. This approach towards science means that empirical observation is falsifiable; since it depends on cultural and social context along with the researcher's knowledge and expectations and these factors are not reliable basis for scientific laws (Godfrey\& Hodgson, 2010).

In accounting, the induction process begins with the observation of accounting data of the reporting units such as sales, purchases, financial ratios, cash flow, debts, capital, and many other data than can be reached via accounting information system. The observations of financial data of a number of companies are meticulously studied and their similar characteristics are found by one's mind. If the data have repetitive relationships, then some principles can be formed and in some cases new thoughts can be induced. If the observations are not influenced by current principles and actions, more innovative thoughts can be induced. For example, based on historical data, the cash to sales ratio of several companies belonged to the same industry might suggest a certain trend. Based on this ratio, we can predict the future cash revenues. This idea is falsifiable. In other words, the macroeconomic factors such as inflation rate, the volume of the liquidity, the interest rate of bonds, and GDP might affect the trend of the cash to sales ratio in the industry and the future revenue collection might not be predictable based on the past trend of sales (Saghafi, 2014).

In accounting, we may observe the changes in share prices simultaneously with the changes in measurement system in the firm. However, another factors (such as a decrease in interest rates) can also justify these changes in share prices. Another criticism leveled at induction is the ambiguity of some of its terms. In order to test a theory, what do the terms "sufficiently big" or "diverse conditions" mean? Another problem of applying the inductive approach in accounting is the difference between the raw data of companies. If the relations between the data are also different, it would be very difficult to deduce the results. Even if an inductive and a deductive reasoning get the same result, the deductive one has more descriptive power and is preferred accordingly (Godfrey\& Hodgson, 2010).

\section{Deductive approach}

The deductive approach constitutes developing of an assumption based on the existing theories and forming a research plan to test the assumption (Wilson, 2010). The deductive approach can be explained using the assumption driven from theory. In other words, the deductive approach includes deducing the results from the premises. When a deductive method is applied for a research project, the author formulates a set of hypotheses that need to be tested and next, using a relevant methodology, tests the hypothesis. Deductive reasoning has specific characteristics that needs be understood. If the premises of deductive reasoning are accepted, then, the conclusion must necessarily be accepted. In a deductive reasoning, the 
contents of the result are implicitly stated in the premises, making such argument a non-ampliative one. If new premises are added to the argument, then the conclusion must still follow. A deductive argument is either valid or invalid and there is no degree of validity. There is no choice or decision in applying such argument and no judgment is necessary for getting the result and conclusion.

Beiske (2007) suggests that the deductive research approach studies a certain theory and tests to see if that theory applies under intended circumstances or not. Deductive approach follows the course of logic precisely. Argumentation begins with a theory and leads to a new assumption. This assumption, is tested via comparison with the observations and finally it would be accepted or rejected (Sneider \& Larner, 2009). In addition, deductive argument can be described as a general to specific (top-down) reasoning process (Pelissier, 2008). While the inductive approach is quite opposite. In other words, the deductive approach includes formulating assumptions and testing them via research process, while inductive studies have nothing to do with assumptions.

An accounting theory based on deductive methodology can be shown as follows.

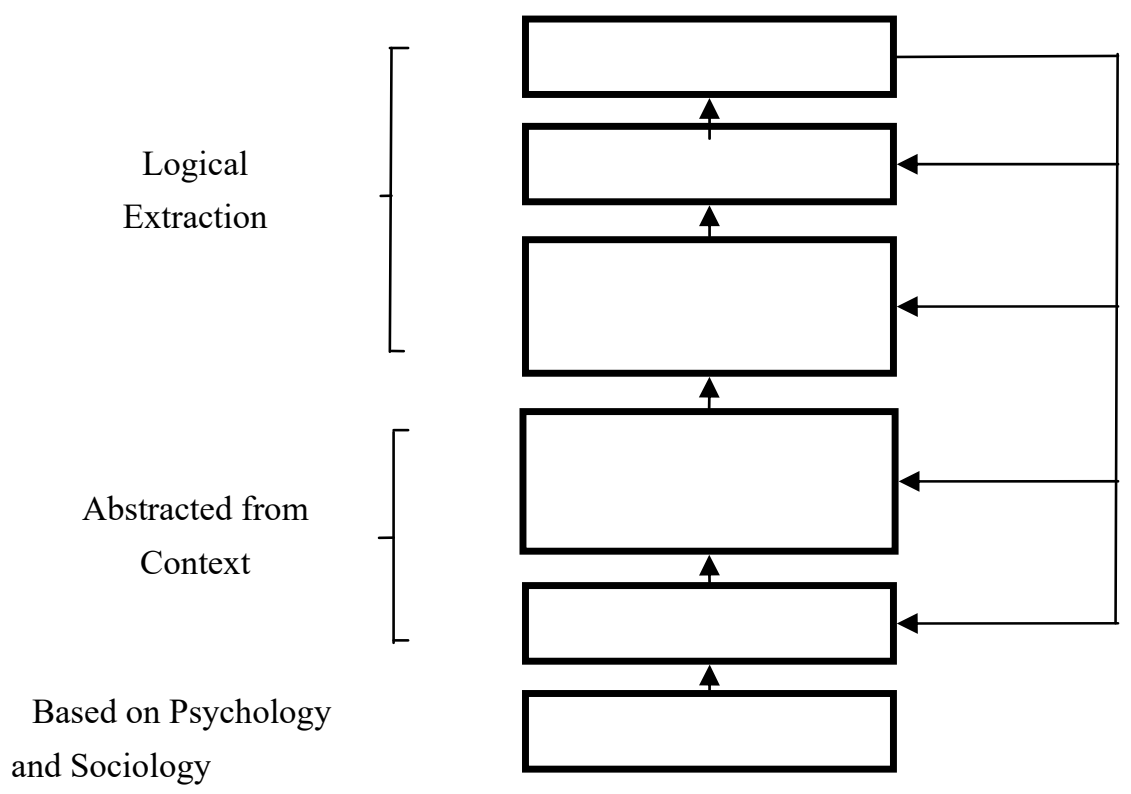

Figure 1. An accounting theory based on deductive methodology ${ }^{1}$

The first stage of forming an accounting theory by using a deductive approach is specifying the basic concepts of accounting (two main concepts are the concepts of proprietary and the entity of the reporting unit). The next stage that is somehow dependent on the first one, is stating the objectives of accounting. Following the objectives, the postulates would be clarified which are dependent on the previous stage. Then, the principles, rules, and procedures are drawn from the established principles using the deductive reasoning. The rules

\footnotetext{
11 Source: Iselin, E. R., (1971), "The objectives of accounting in an accounting theory, based on deductive methodology”, University of Queensland Press, St. Lucia, Queensland, Volume 2 (1)
} 
and procedures can be practically used for creating the result. These results are used as a test of the fundamental theory (Iselin, 1971). In deductive approach, the research method does not depend on the current accounting system under any conditions. Accordingly, the obtained theory does not inherit any of the weaknesses and shortages of the current accounting system. Furthermore, based on this approach, the assumptions of a theory would be clearly specified. Thus, they can be studied meticulously. As a result, if there is any disagreement over the results, the argument would be quickly directed towards the main causes of disagreements.

Some of the criticisms about the deductive approach can be due to misunderstanding. Expecting a theory to necessarily be practical is not a right expectation. If a theory can present a framework for describing and developing new thoughts and practices, that theory is a useful one. In most cases, the technological application of the existing knowledge is not possible. The technology of providing, selecting and reporting information might not be that high to be able to operationalize the procedures obtained from the deductive approach (Saghafi, 2014).

\section{The role of inductive and deductive reasoning in accounting research}

The databases have made it easy for researchers to explore relationships among different data and get generalisable results using statistics knowledge. Therefore, most of the research projects are conducted using inductive argumentation. Obviously, the researchers have a suitable understanding and mastery of research topic and related variables, that is, they use deductive approach at the beginning of the project, and then deducing the results. Since the deductive approach requires a perfect understanding of accounting and related sciences such as economics, finance, psychology, sociology and a close familiarity with the accepted social values, so mostly research groups are capable to conduct research using the deductive methodology. As a result, most of accounting dissertations have been done applying inductive approach. Rarely do the researchers apply the deductive approach for their dissertations (Saghafi, 2014).

Similar to the descriptive and prescriptive approaches, a precise analysis of the contrasts between deductive and inductive approaches suggest that this contrast cannot be useful. The most important problem is the fact that while distinguishing inductive theorizing from deductive one is correct, it does not mean that there are two different theories accordingly. The inductive and deductive theorizing are two complementary stages of constructing any theory, in a way that induction precedes deduction. While developing the theories, the researchers usually act inductively. In order to understand and explain the phenomena, they make the necessary observations, collect the evidence, and then test them. Other researchers with an interest in a similar topic might present different explanations based on the same evidence which leads to debates, more research and complementary explanations. Almost always, the objective is to present a common and agreed upon understanding of the concerning issue. The main method which has caused progress is testing the assumption. This is where deduction takes action. Having a possible explanation allows the progress of testable assumptions, this means if the current theory is free from any fault, then under certain conditions, specific outputs can be expected. These results have been excavated from the 
intended theory using deductive method. The result of such a testing of an assumption can contribute to providing explanations which finally lead to either supporting or rejecting the tested assumption (Roslender, 1992).

Amongst the progressive accounting research studies, one can refer to the work of Paton \& Littleton (1940) titled "An Introduction to Corporate Accounting Standards". The project reflects both analytical thinking of Paton and inductive approach of Littleton and was a quasi-codification of accounting principles that instead of generalizing from practice, had developed deductively (Mattessich, 2008).

\section{The role of inductive and deductive reasoning in developing accounting theory}

Reasoning style is of great significance for theorizing. Developing a theory of accounting was initially based on induction, i.e. forming ideas or theories through observation. From 1920s to 1960s, the accounting theories were commonly based on the observation of what the accountants did in practice, that is, they were formed based on the induction process. This contrasts the method which forms theories based on deductive reasoning which relies on using logic instead of observation. Referring to using observations in developing generalizable theories (inductive reasoning) after observing what accountants do in practice, the common practice turns into accounting doctrines or conventions (e.g. conservatism doctrine). The significant theories of this period of time include Paton (1992), Hatfield (1927), Paton and Littleton (1940) and Canning (1929). Researches based on inductive approach were under a lot of criticism. In 1960s and 1970s, although some of the researchers in accounting continued to use inductive approach, a different approach gained ground. This approach was looking for prescribing specific accounting practices, therefore it was not derived from the existing accounting practices. In other words, the theories of financial accounting were not formed based on observing the accounting practices, rather most of the theories developed at that time were based on extending arguments whereby the researcher believed the accountants should follow. Instead of applying inductive arguments, these theories were based on deductive arguments. At this period, inflation prevailed in most of the countries of the world and as a result, most of relevant research and theories were trying to display the limitations of historical cost accounting and to develop better approaches for evaluating the properties at the time of fast changing prices. Since the mid-1970s till the late 1970s, considerable developments occurred in terms of a shift of focus of accounting research and theories. At that time, a huge volume of accounting research was conducted with the aim of explaining and predicting the accounting procedures instead of prescribing particular viewpoints. This was, in fact, another step taken by most of accounting researchers towards predictive research and away from prescriptive research. However, there are still many researchers who do prescriptive research (Deegan, 2011).

The development of financial accounting theory started in the late 1930s and was a reaction to public criticism of financial accounting. First the AAA was established with 20 propositions regarding costs, values, income, and capital and surplus (AAA, 1936). This was not a comprehensive financial accounting theory, it was merely a theoretical review of some of the specific accounting practices using a deductive approach. This statement strengthened 
the conservatism and historical cost accounting principles and supported a comprehensive concept of income. Later on, Paton and Littleton extended the 1936 statement of AAA (Paton \& Littleton, 1940). It can be claimed as the first institutional attempt to develop a theory of accounting and it is certainly the first conceptual framework of accounting standards. The statement enjoyed an inductive approach towards accounting theory and provided an explanatory framework for accounting based on historical cost. Notions such as entity, going concern, historical cost, and the conformity of these concepts was explained in chapters of the statement on costs, income, benefit, and surplus by Paton and Littleton. Nevertheless, the professionals and academicians were not convinced by Paton and Littleton's entity concept. The significance of their study is manifested in the fact that most of its basic and fundamental ideas are still present in the conceptual framework and standards of modern day accounting.

Littleton (1953) believed that theory and practice are a single subject in financial accounting. There is no surprise to see that in The Structure of Accounting Theory, he tries to defend the historical cost accounting via inductive approach towards theory. The book puts emphasis on the view of general objectives for financial reporting with the aim of stewardship, and applied inductive approach for theorizing and presented an accounting theory within the framework of objectives, concepts, and principles. It also provided a considerable comfort and ease for the professionals in the field who were dependent on an income-centered financial reporting system based on historical cost. However, Littleton's work can be approached from a different angle as well. This conforms to the philosophy of next theoretical view, the positive accounting theory. The theory takes the role of theorists as observers and embarks on explaining and predicting real procedures instead of prescribing alternative procedures (Watts and Zimmerman, 1986).

The early theorists preferred to use an inductive approach based on the observation of real practices. Nevertheless, gradually the financial accounting theory was influenced by economic thinking and due to the significance of the concepts of profit in economic theory, the accounting theory put its focus on the fiscal year profits and the relevant problems. Chambers (1966) emphasized on a reporting system based on the net market value in which the financial position was taken as the core and profit as a derivative. His theory was stemming from pricing experiences, management education, concerns regarding inductive reasoning by previous theorists, weaknesses in methodology of previous theories, and increasing evidence of unreliability of reported figures. Chambers presented a deductive theory of accounting using ideas from a range of disciplines including communications, economics, management, mathematics, measurement, organizational behavior, and philosophy. Chambers' first project was presented back in 1955 consisted of four fundamental principles, including: units, logical management, financial statements, and accounting as a service. He developed these ideas in various papers using a prescriptive thinking and a deductive approach. The importance of Chambers' work in the history of financial accounting relates to his methodology in theorizing. Chambers' deductive work was a direct challenge to Paton and Littleton's inductive and pragmatic approach. His heritage can be seen in later theories of accounting, and also in practice. Increasing attention to financial position and using net realizable value in order to actualize the fair value accounting are manifestations of 
Chambers' efforts (Lee, 2009).

Other classic theorists of accounting theory in the 1960s included Edwards and Bell (1961), Monitz (1961), Sprouse and Moonitz (1962), Mattessich (1964), Graddy (1965), Ijiri (1967), and Sterling (1970). Each of them has brought up a formal theoretical structure and has followed deductive and normative prescription approach. In the mid twentieth century, inductive approach was replaced by deductive approach. In the early years of financial accounting theory, inductive approach's objective was that practical usages becoming the subject of future theories. Sometimes in recent decades, deductive arguments have been involved in changing accounting practices, e.g. currents costs accounting in early 1980s and cash flow accounting since 1980s. Those participated in this field included professionals and academicians who first used inductive approach and later deductive one, and then returned to the inductive approach (Lee, 2009).

The inductive theories of accounting have been formed through observation and generalization of the observations and measurements. This view is probably the oldest technique of theory construction in accounting. The accounting procedures that have been formed empirically or even accidentally are observed, the observations are generalized, and finally, these generalizations are documented as accounting theory. Riahi-Belkaoui (2004) mentions that the theorists such as Hatfield, Gilman, Littleton, Paton, and Ijiri can be considered as inductive theorists.

The history explained here, introduced two kinds of theories and theorists, the first referring to individual efforts for explaining and predicting how the profession of accounting works. These replaced from inductive studies on pragmatic procedures, to imperative prescriptions that became competitive and finally put aside as non-practical, and along with empirical observations of what is done in practice. The result of such a theory was lack of success in challenging the problems related to the conventional practice. The second kind of theory and theoretician related to the basic conceptual framework that supported the conventional practice (Lee, 2009).

Deegan \& Unerman (2006) stated that there is no universal agreement on how accounting theories should be developed. Accounting theories were developed applying a combination of deductive and inductive arguments. Hendriksen (1982) stated that all theories need to have elements of both deductive and inductive arguments. While the deductive approach begins with extensive and general aims and presumptions and ends with specific methods and rules, the inductive approach, on the other hand, follows a totally adverse model: the generalized results are taken from detailed observations and measurements. It is notable that the data that are chosen for observations to be used in inductive reasoning, are selected by deductive reasoning, therefore the development of theory is an iterative process (Vorster, 2007).

\section{The role of inductive and deductive reasoning in developing accounting standards}

Standard setters introduced the accounting theory through conceptual framework and standards. What is expected from the theory of accounting is to enable the standard setters to deduce standards. Developing accounting theory and the project of developing the conceptual 
framework need identifying something that can be used for deducing the standards.

Following the global stock market crisis of 1929, the US government tended towards increasing the regulation of financial markets. Later in 1934, SEC was established to monitor the financial market. In the meantime, the need arose for a deductive accounting theory. The vast economic and social damages caused by the collapse of the market forced AAA to publish A tentative statement of accounting principles underlying corporate financial statements (1936). This was the first step in the deductive approach towards the accounting theory that happened in line with a change of approach in 1933 to support investors and creditors (Sutton, 2011).

With the revision of 1957, titled Accounting and reporting standards for corporate financial statements, the efforts of AAA in developing an accounting framework, which were originally based on inductive approach, gradually changed to a deductive one (Riahi-Belkaoui, 1981). In 1957-1964, some questioned the suitability of the inductive approach for extracting accounting standards and opted for a more deductive and conceptual approach. A disagreement has always been existed between the AICPA and AAA in this regard. AAA supported deductive approach. This point displays the differences over the standard setting methods. In inductive approach, standard setters tend to set standards with a firefighting approach which leads to incompatible standards. However, deductive approach needs a more conceptual view as a basis from which deduction can be extracted.

In the 1960s, the failure of inductive approach of standard setting which held sway in those days, made the deductive approach more tangible (Gore, 1992).

Moonitz (1961) in ARS no. 1, titled "The basic postulates of accounting" stated that they have reached to the conclusion and in order to develop fundamental assumptions and principles of accounting, emphasis should be put on deductive argument (Dennis, 2014). ARS no. 7 titled Inventory of generally accepted accounting principles for business enterprises (1965), was written by Paul Grady. This research followed the conservative views of Hatfield and Moore (1938), and Paton and Littleton (1940). The study applied inductive approach and specified ten concepts. Later on, Grady presented the generally accepted principles of accounting precisely and as a set of goals, emphasizing the performance of accounting (Chatfield, 1996).

A statement of basic accounting theory (ASOBAT) was published a year later. ASOBAT (1966) can be considered as a significant turning point (Young, 2006). It rejected previous opinions, including Grady's report (1965). Grady's report challenged Paton and Littleton's idea. Paton and Littleton (1940) had used a thoroughly inductive approach in their dissertation (Mattessich, 1995). ASOBAT (1966) considered accounting as a financial reporting system (Sutton, 2011). Chambers (1966) suggested that rule setting is a deductive process. Having assumed the principles through logical deduction, one can get the rules. Chambers believed that Paton's (1992) book titled "The theory of accounting" for the first time pointed to the topic of deductive extraction of a set of rules out of a set of postulates. Littleton's (1953) book titled "The structure of accounting theory" was formed based on the idea that as far as there are supporting explanations, the rules seem to have been extracted 
deductively (Chambers, 1966).

Prior to 1970s, the American and British accountants' procedure for achieving consistency in financial accounting was to use an inductive approach based on logical justification of what has happened in practice. However, this method was criticized because only problems were dealt with when they arose. This led to overlapping and contradiction. Then, they followed the deductive approach based on theoretical postulates. However, this approach was also criticized because it was unrealistic. This led to the creation of demand for a conceptual framework for providing a set of integrated principles of financial reporting (Collis et al, 2012).

The important decision in the conceptual framework project was for the framework to be based on a deductive approach. As it was mentioned before, this deductive approach had already been used, the most famous cases were in ARS no. 3 in 1962 and Trueblood study group in a report titled "Objectives of financial statements" in 1973. The opposite approach had also been already used, the most famous cases were in APB no. 4 (1970) titled "Basic Concepts and accounting principles underlying financial statements of business enterprises" (Graham and Carmichael, 2012).

Regardless of various merits and flaws of both approaches, the main difference between them is that the inductive approach suggests using old solutions for solving modern problems, while the deductive approach tends towards applying new solutions for solving old problems. Therefore, the resolve of FASB for using a deductive framework, has increased the supporting of significant changes in the GAAP. Accordingly, the conceptual framework project has been and is controversial (Graham and Carmichael, 2012). Regarding the accounting standards, the main element in establishing the suggested rule will be induction. There can be no action which is totally abstract. Although, when it is established, such a broad philosophy can be helpful in developing a relevant set of standards. However, this is not an inductive process and its product, the prescriptive standards of accounting, are not theoretical institutions at all. They are guidelines for action which have been proposed by a body established to serve this goal. If the aim of accounting standards is to form an integrated set of optimum accounting practices, these standards need to be deducted from a theoretical institutions with an upper hand, which is in fact the conceptual framework. In this situation, it is the real standards that form the theory in question. Regarding the inductive theories, those practices that gain pervasive applications, constitute the positive accounting theory. However, regarding the deductive theory, standards that deduced from meta-theory play this role (Roslender, 1992).

Dennis (2014) investigated the type of reasoning used in standard setting decisions. He proposed that when such decisions are accompanied by a consideration of the intended goals, the type of reasoning should not be taken as deductive but as a form of practical reasoning. Decision making in standard setting is an argument for the demand of developing standards. In the rule-based approach of standard setting, the standard setter wants all of the rules that are related to the intended goal. It is easy to set standards in this approach since all the standard setter needs to do is identify the rule suitable for a certain goal and conclude that he 
wants to publish it. In this situation, no decision or option is involved. This type of argument is deductive and the conclusions necessarily follow the premises. In this approach, the rule is something that needs to be followed under all circumstances. Regarding accounting standards, this means that there is no probability of disagreement on what has been meant by a particular rule, since in deduction, if the premises are accepted, the conclusion will necessarily follow (Dennis, 2014).

If the argument is not deductive, then such an argument involves option or decision and there is a need for judgment in conclusion. The concluded result is not necessary, therefore an element of option or decision will be involved (Salmon, 1992). When a principle-based approach is used for extracting specific standards, judgment is needed. This means, standard setters that use principle-based approach for extracting specific standards should use judgment in their argument. In this approach, the argument applied is a deductive one. In the subject of auditing, standards may require the auditor to search for pieces of evidence for confirming a claim in financial statements. Here, searching for evidence, they have used inductive instead of deductive argument, and judgment should be applied (Dennis, 2014).

\section{Summary and conclusion}

In this paper, while explaining deductive and inductive reasoning, we elaborated on their role in accounting theory, developing standards, and accounting research. Accounting theory has been developed by the process of accounting research and has been modified gradually. Accounting theory, along with political factors and economic circumstances, is one of the main factors influencing the development of accounting standards. The standards and other announcements of policy making organizations have been interpreted and executed.

In the process of developing an accounting theory, the reasoning method is highly significant. Developing the theory in the first place has a deductive process in social sciences. The researcher via observing phenomenon or studying the literature, presents a theory over why a phenomenon has happened. As it was mentioned, in the early years of developing accounting theory, inductive approach was used more and the goal was for practical applications to be the subject of later theories. Then, a general shift in approach towards research based on deductive reasoning happened. However, after a few years, the focus of research and accounting theory was again shifted towards the inductive approach. Therefore, as it was mentioned, accounting theories have been formed through combining deductive and inductive arguments. Accounting theorists generally begin with inductive reasoning and change their course towards a deductive approach in order to improve the theory through development of understanding and explanation power.

In accounting research, inductive reasoning is used more in qualitative research. While inductive reasoning is more applicable for quantitative research. However, inductive and deductive research methods are not mutually exclusive, and they are usually used to supplement each other. Since, the researchers use their knowledge about the practical procedures of accounting. As Riahi-Belkaoui (1981) points it out: the general pronouncements are formed via an inductive process, but the principles and methods are obtained through deductive approach. He also believes that when Littleton, an inductive 
theorist, cooperates with Paton, a deductive theorist, it shows a compromise between the two approaches. As an example, inductive approach may be used for evaluating the suitability of a set of premises which had been selected based on deductive system. The researchers usually begin with the results of other research and present new hypothesis, and then test the hypothesis. Inductive research in accounting can shed light on present events and relations in the business context. This kind of research, can in turn be effective in the process of standard setting. A process based on which deductive reasoning will help to determine the rules that need prescription.

In setting accounting standards, if the standard setting approach is rule-based, then the reasoning method is deductive. Nevertheless, if the standard setting approach is principle-based, then inductive reasoning is more applicable. Nowadays, according to the policy of moving towards principle-based approach in setting accounting standards, it can be concluded that the deductive approach is gradually replaced by the inductive approach in setting accounting standards. In inductive approach, the truth or falsity of the premise is not dependent on other premises, instead it needs to be confirmed empirically. In this approach, the truth of premises depends on the observation of sufficient cases of repeated relationships. Accounting premises that have been obtained via inductive argument, show the specific accounting procedures only with a high probability. On the other hand, accounting premises that have been obtained via deductive argument, lead to specific accounting procedures along with certainty.

The lack of philosophical issues and subjects in accounting discussions is quite tangible. This paper was meant to fill this gap taking a descriptive approach and to bring up some issues. Future research can, while investigating these issues more precisely, study the role of different type of reasoning in research and standards of different fields of accounting including auditing and management accounting in particular.

\section{References}

AAA. (1936). A Tentative Statement of Accounting Principles Underlying Corporate Financial Statement (New York: AAA).

AAA. (1977). Statement on Accounting Theory and Theory Acceptance (Evanston, IL: AAA).

Babbie, E. (2014). The basics of social research. ( $6^{\text {th }}$ ed). Wadsworth, Cengage Learning, USA

Beiske, B. (2007). Research methods: Uses and limitations of questionnaires, interviews and case studies, GRIN Verlag.

Bernard, H.R. (2011). Research methods in anthropology. (5th ed). Alta Mira Press.

Chambers, R. J. (1966). Accounting, evaluation and economic behavior. New Jersey. Prentice-Hal

Chatfield, M. (1996). The History of accounting: An international encyclopaedia. New York: Garland. 
Collis, J., Holt, A., \& Hussey, R. (2012). Business accounting: An introduction to financial and management accounting. ( $2^{\text {nd }}$ ed). New York: Palgrave Macmillan. http://dx.doi.org/10.1080/00014788.2012.667969

Deegan, C. (2011). Financial Accounting Theory. (2nd international revision). Mcgraw-Hill Higher Education.

Deegan, C., \& Unerman, J. (2006). Financial Accounting Theory, European Edition. McGraw Hill.

Dennis, I. (2014). The nature of accounting regulation. New York: Routledge, Taylor \& Francis Group.

Lee, T.A. (2009). Financial accounting theory. In J.R. Edwards, \& S.P. Walker (Eds), The Routledge companion to accounting history (pp. 140-156). London: Routledge. http://dx.doi.org/10.1080/09585200903246817

Goddard, W. \& Melville, S. (2004). Research methodology: An introduction. (2nd ed). Blackwell Publishing.

Godfrey, J., Hodgson, A. (2010). Accounting Theory. (7th ed). Wiley. ISBN: 978-0-470-81815-2.

Gore, P. (1992). The FASB conceptual framework project. 1973-1985: An analysis. Manchester, Angleterre: Manchester University Press.

Graham, L., \& Carmichael, D. (2012). Financial accounting and general topics. (12th ed). Hoboken, N.J.: John Wiley \& Sons.

Iselin, E. R. (1971). The objectives of accounting in an accounting theory based on deductive methodology. St. Lucia: University of Queensland Press.

Krivogorsky, V. (2011). Law, corporate governance, and accounting European perspectives. New York: Routledge.

Littleton, A. C. (1953). Structure of Accounting Theory. Monograph No. 5. Sarasota, Florida: American Accounting Association.

Lodico, M.G., Spaulding, D.T., \& Voegtle, G.H. (2010). Methods in Educational Research: from theory to practice. ( $2^{\text {nd }}$ edition). Wiley.

Mattesich, R. (1995). Critique of accounting. An Examination of the Foundations and Normative Structure of an Applied Discipline. Westport, CT: Quorum Books, 304 pp.

Mattessich, R. (2008). Two hundred years of accounting research: An international survey of personalities, ideas and publications (from the beginning of the nineteenth century to the beginning of the twenty-first century. London: Routledge.

Moonitz, M., (1961). The Basic Postulates of Accounting. Accounting Research Study No. 1, New York, AICPA. 


\section{Macrothink}

Asian Journal of Finance \& Accounting

ISSN 1946-052X

2016, Vol. 8, No. 1

Neuman, W.L. (2003) Social Research Methods: Qualitative and Quantitative Approaches. Allyn and Bacon.

Pellissier, R. (2008). Business Research-Made Easy. Juta \& Company Ltd., Kenwyn, ZA.

Riahi-Belkaoui, A. (1981). Accounting theory. New York: Harcourt Brace Jovanovich.

Riahi-Belkaoui, A. (2004). Accounting theory. $\left(5^{\text {th }}\right.$ ed). London: Thomson.

Roslender, R. (1992). Sociological perspectives on modern accountancy. London: Routledge.

Saghafi, A. (2014). Accounting theories. ( $3^{\text {rd }}$ ed). Iranian Accounting Association.

Salmon, M.H. (1992). Philosophy of the social sciences. In M.H. Salmon, J. Earman, C. Glymour, J.g. Lennox, P. Machamer, J.E. McGuire, J.D. Norton, W.C. Salmon \& K.F. Schaffner (eds), Introduction to the philosophy of science, pp. 404-425. Indianapolis, IN: Hackett.

Snieder, R., \& Larner, K. (2009). The Art of Being a Scientist: A Guide for Graduate Students and their Mentors, Cambridge University Press. http://dx.doi.org/10.1017/cbo9780511816543

Sutton, D. (2011). Conceptual framework coherence: why and how. Victoria University of Wellington. Working paper series, Working Paper No. 88. http://dx.doi.org/10.2139/ssrn.2028740

Vorster, Q. (2007). The Conceptual Framework, Accounting Principles and what we believe is true. Accountancy S; Accounting \& Tax periodicals, pp. 30-33.

Watts, R.L., \& Zimmerman, J.L. (1986). Positive accounting theory. Englewood Cliffs, NJ: Prentice-Hall.

Wilson, J. (2010). Essentials of Business Research: A Guide to Doing Your Research Project. SAGE Publications.

Young, J.J. (2006). Making up users. Accounting, Organizations and Society, 31(6). http://dx.doi.org/10.1016/j.aos.2005.12.005

\section{Copyright Disclaimer}

Copyright for this article is retained by the author(s), with first publication rights granted to the journal.

This is an open-access article distributed under the terms and conditions of the Creative Commons Attribution license (http://creativecommons.org/licenses/by/3.0/). 